\title{
DSP improvement of a vector speed induction motor control with a RST and adaptive fuzzy controller
}

\author{
Mihoub Youcef ${ }^{1}$, Toumi Djilali², Sandrine Moreau ${ }^{3}$, Hassaine Said ${ }^{4}$, Daoud Bachir ${ }^{5}$ \\ ${ }^{1,2,4,5}$ Energetic Engineering and Computer Engineering Laboratory, Electrical Engineering Department, University of \\ Tiaret, Tiaret, Algeria \\ ${ }^{3}$ Laboratory of Informatics and Automatic Systems (LIAS), Poitiers University, Poitiers, France
}

\begin{tabular}{l} 
Article Info \\
\hline Article history: \\
Received Sep 23, \\
Revised Jun 11, 2020 \\
Accepted Apr 11, 202 \\
\hline keywords: \\
Adaptive control \\
dSPACE1104 \\
Fuzzy control \\
Induction motor \\
RST \\
Vector control
\end{tabular}

Article Info

Article history:

Received Sep 23, 2019

Revised Jun 11, 2020

\begin{abstract}
The aim of this work is to improve the dynamics and to overcome the limitation of conventional fixed parameters PI controller used in induction motor (IM) field-oriented control (FOC). This study presents and implements a RST and an adaptive fuzzy controller (AFC) to enhance variable speed control. Theoretical background of theses controllers is outlined and then experimental results are presented. Practical implementation has been realized on a board with a $1.1 \mathrm{KW}$ IM supplied by $10 \mathrm{KHz}$ space vector pulse width modulation current regulated inverter used as power amplifier consisted of $300 \mathrm{~V}, 10 \mathrm{~A}$ IGBT and Matlab/Simulink environment. Test benches have been established under different operating conditions in order to evaluate and compare the performances of the PI, IP, and polynomial RST and adaptive fuzzy controllers. Parameter variations for the rotor and the inertia moment variation were done in order to compare and verify the robustness of each controller. High dynamic performances and robustness against parameters variation were obtained with the use of both RST and AFC.
\end{abstract}

This is an open access article under the CC BY-SA license.

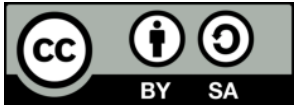

Corresponding Author:

Mihoub Youcef

Department of Electrical Engineering

Electrical Engineering Department, Universit of Tiaret

$\mathrm{BP}^{\circ} 78$ Zaaroura Tiaret

Email: Youcef.mihoub@univ-tiaret.dz

\section{INTRODUCTION}

IM is the most potential candidate in the industrial field working in difficult environments. It is highly recommended and presents many advantages, such as being robust, simple and relatively cheap with high mass torque and absence of brush collector system [1]. The main applications are pumping, ventilation and machine tools. The field-oriented control (FOC) provides high level performance drive and permits a decoupled control of torque and flux [2]. Nowadays, the use of FOC with IM becomes the most used strategy. IM becomes a superior choice over direct current (DC) drives.

PI controller is widely used because of its implantation simplicity but its performances are degraded under external disturbances, parameters variations and temperature changes [3], [4]. The dynamic torque response is deteriorated due to the differences between measured and actual motor parameters [5]-[6]. Many researchers have focused on developing accurate mathematical models and different model-free methods have been developed [7], [8]. These methods include sliding mode control (SMC) [4], [9], [10], back-stepping control [11]-[13], the passivity based approaches [14],neural networks (NNs) [15]-[17] and fuzzy control (FC) system [18]-[21]. However, NNs learning algorithms are in general still complex and increases the computational burden of NNs. 
Parameter adaptation with fuzzy logic is one option to improve the PI controllers [22]. This can be achieved using model reference adaptive control (MRAC) [23], [24], sliding mode or self tuning PIDs [16], [25]-[30]. The main advantages of FC compared to conventional one is that no exact mathematical model and also exact system parameters are needed. In [31]-[32], direct fuzzy model reference learning controller has been discussed. Also in [33]-[35], it has been proved that fuzzy controllers improve the tracking performances when rotor time constant affect the decoupling in FOC strategy. But in the other hand the software implementation presents limitation due to the high computational burden. As solution, fuzzy rules reduction and membership functions optimization were proposed in [36]. However, the performance investigations were limited to simulation results.

Conventional PI fixed parameters controller is less robust than a RST controller against disturbances. The RST polynomial controller can improve the system performances in terms of overshoot, rapidity, elimination of disturbance, and maintain a high level of performance. RST control is based on a synthesis of control law. It has been proved to be efficient and successful for a lot of industrial applications [37-39]. It is based on a polynomial, leading to transfer functions. The RST polynomials are calculated by the resolution of Bezout's equation [39].

In this paper, an adaptive fuzzy speed controller is used to adjust the PI gains. Then the RST speed controller is then used to be compared to the other developed speed controllers. Dspace 1104 digital signal processor fully programmable from the MATLAB/Simulink environment is used for the experimental implementation. Experimental tests are developed for step and ramp speed changes with speed inversion, which represents an extreme transient condition. Results are presented and discussed in each case. To confirm the robustness of each controller, parameter variation tests have been also applied.

\section{THE PROPOSED IM DRIVE CONTROL SYSTEM}

The proposed IM drive control system is based on an adaptive fuzzy speed controller to adjust the PI gains. The error, the change of error between the actual and the reference speed and saturation variable depending on the torque producing current are used as input. Fuzzy Takagi Sugeno controller type is used with singleton output values which have to adapt instantaneously the PI gains. Secondly, the RST speed controller synthesis with optimal pole placement relying on natural frequency and damping ratio of the system. Figure 1 shows the basic building block diagram of the proposed drive control system.

Where $v_{s a b c}$ and $i_{s a b c}$ are respectively the three-phase stator voltages and currents, $\left(v_{s d}, v_{s q}\right)$ and $\left(i_{s d}, i_{s q}\right)$ are respectively the stator voltages and currents in the synchronously rotating reference frame, $\left(\varphi_{r d}, \varphi_{r q}\right)$ are the $\mathrm{d}$ and $\mathrm{q}$ axis components of rotor fluxes, $\left(v_{s \alpha}, v_{s \beta}\right)$ and $\left(i_{s \alpha}, i_{s \beta}\right)$ are respectively the stator voltages and currents in the stationary reference frame, $\Omega$ and $\omega_{s}$ are respectively the mechanical rotor speed and the electrical synchronous speed $(\mathrm{rad} / \mathrm{s}), \theta_{s}$ is the rotor flux vector electrical position and $(.)^{*}$ denotes the reference value of the concerned variable.

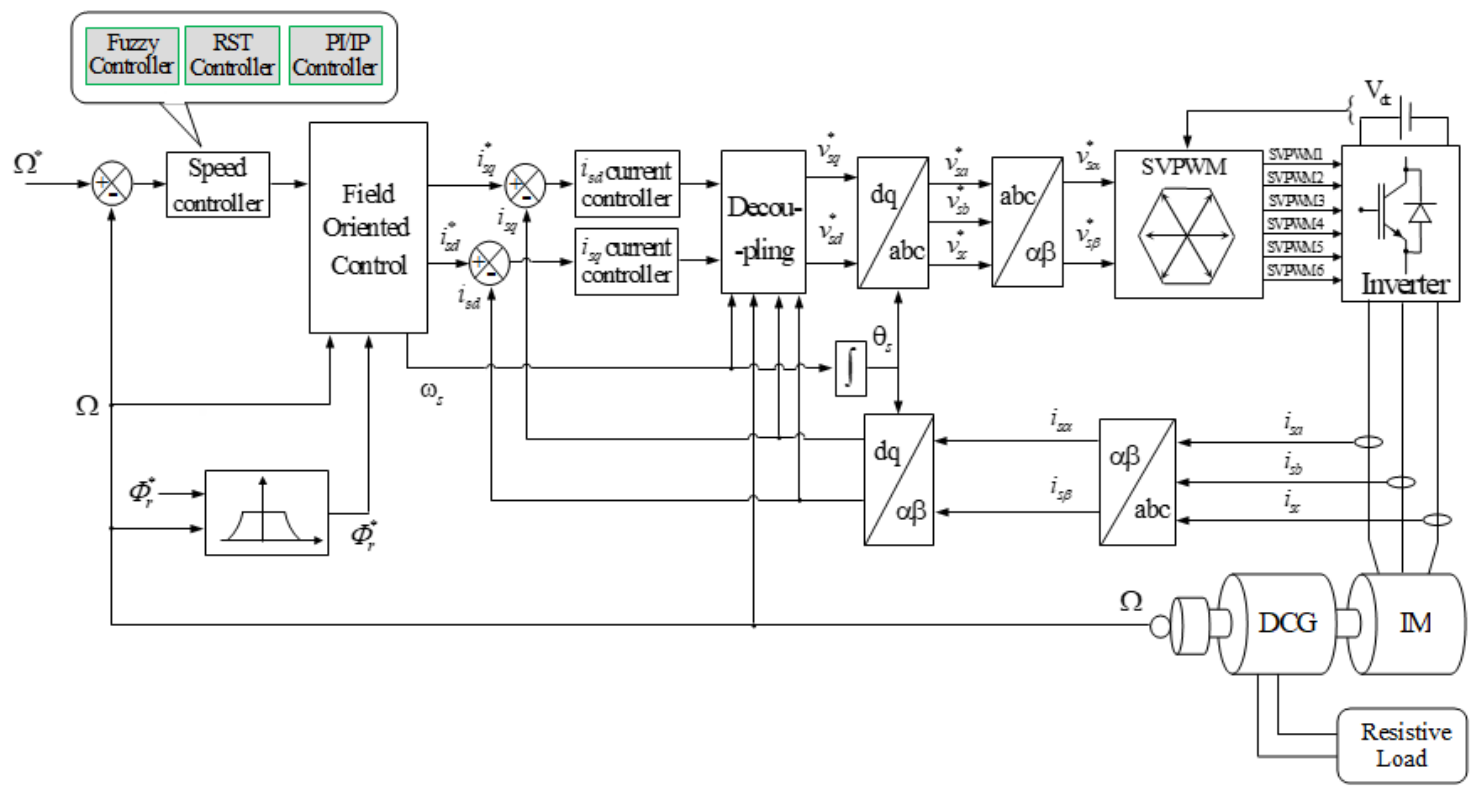

Figure 1. Basic drive system block diagram 
Using stator currents and rotor fluxes as state variable, the IM model in synchronous reference frame can be represented by the following equation:

$$
\left\{\begin{array}{l}
\frac{d i_{s d}}{d t}=\frac{-\left(R_{s}+\left(M_{s r} / L_{r}\right)^{2} R_{r}\right)}{\sigma L_{s}} i_{s d}+\omega_{s} i_{s q}+\frac{M_{s r} R_{r}}{\sigma L_{s} L_{r}^{2}} \Phi_{r d}+\frac{M_{s r}}{\sigma L_{s} L_{r}} \omega \Phi_{r q}+\frac{1}{\sigma L_{s}} v_{s d} \\
\frac{d i_{s q}}{d t}=\frac{-\left(R_{s}+\left(M_{s r} / L_{r}\right)^{2} R_{r}\right)}{\sigma L_{s}} i_{s q}-\omega_{s} i_{s d}-\frac{M_{s r}}{\sigma L_{s} L_{r}} \omega \Phi_{r d}+\frac{M_{s r} R_{r}}{\sigma L_{s} L_{r}^{2}} \Phi_{r q}+\frac{1}{\sigma L_{s}} v_{s q} \\
\frac{d \Phi_{r d}}{d t}=\frac{M_{s r} R_{r}}{L_{r}} i_{s d}-\frac{R_{r}}{L_{r}} \Phi_{r d}+\left(\omega_{s}-\omega\right) \Phi_{r q} \\
\frac{d \Phi_{r q}}{d t}=\frac{M_{s r} R_{r}}{L_{r}} i_{s q}-\frac{R_{r}}{L_{r}} \Phi_{r q}-\left(\omega_{s}-\omega\right) \Phi_{r d} \\
\frac{d \Omega}{d t}=\frac{p M_{s r}}{L_{r} J}\left(i_{s q} \Phi_{r d}-i_{s d} \Phi_{r q}\right)-\frac{F}{J} \Omega-\frac{1}{J} T_{L}
\end{array}\right.
$$

Where $R_{S}, R_{r}$ are respectively the stator and rotor winding resistance, $L_{S}, L_{r}$ are respectively the stator and rotor inductance, $M_{s r}$ is the mutual inductance, $p$ is the number of pole pairs, $J$ is the inertia moment, $F$ is the viscous friction coefficient, $T_{e}, T_{L}$ are respectively the electromagnetic and load torques $\sigma$ is the total leakage factor, $T_{r}=\frac{L_{r}}{R_{r}}$ is the rotor time constant and $\omega$ is the electrical rotor speed $(\mathrm{rad} / \mathrm{s})$.

The vector control principle is to align the $d$ axis of the $(d, q)$ rotary reference frame with the rotor flux vector for the $I M$, so as to control separately the electromagnetic torque and the rotor flux. According to (1), the model of the motor can be expressed by the following equations:

$$
\left\{\begin{array}{l}
\frac{d i_{s d}}{d t}=\frac{-\left(R_{s}+\left(M_{s r} / L_{r}\right)^{2} R_{r}\right)}{\sigma L_{s}} i_{s d}+\omega_{s} i_{s q}+\frac{M_{s r} R_{r}}{\sigma L_{s} L_{r}^{2}} \Phi_{r}+\frac{1}{\sigma L_{s}} v_{s d} \\
\frac{d i_{s q}}{d t}=\frac{-\left(R_{s}+\left(M_{s r} / L_{r}\right)^{2} R_{r}\right)}{\sigma L_{s}} i_{s q}-\omega_{s} i_{s d}-\frac{M_{s r}}{\sigma L_{s} L_{r}} \omega \Phi_{r}+\frac{1}{\sigma L_{s}} v_{s q} \\
\frac{d \Phi_{r}}{d t}=\frac{M_{s r} R_{r}}{L_{r}} i_{s d}-\frac{R_{r}}{L_{r}} \Phi_{r} \\
0=\frac{M_{s r} R_{r}}{L_{r}} i_{s q}-\left(\omega_{s}-\omega\right) \Phi_{r} \\
\frac{d \Omega}{d t}=K . i_{s q}-\frac{F}{J} \Omega-\frac{1}{J} T_{L}
\end{array}\right.
$$

with $K=\frac{p M_{S r}}{L_{r} J} \Phi r$

Vector control of IM is used in direct field orientation, where sensors or models are used to calculate the position and the magnitude of the rotor flux or indirect method, where the speed position is used. The system contains two control loops in $\mathrm{d}$ and $\mathrm{q}$ axis as shown in Figure 1.

\subsection{Current control in $d$ axis}

The voltage transfer function (TF) between $\mathrm{v}_{\mathrm{sd}}$ voltage and $\mathrm{i}_{\mathrm{sd}}$ current is given by:

$$
\frac{i_{s d}}{v_{s d}}=\frac{1}{R_{S}+\sigma L_{S} s}, \text { where } s \text {, is the Laplace operator }
$$

Using the compensation synthesis technique, the closed loop TF with PI controller is given by:

$$
\frac{i_{s d}}{i_{s d}^{*}}=\frac{1}{1+\left(\sigma L_{s} / K_{p d}\right) s}
$$

Imposing the settling time $t_{r}$, the obtained dynamic is fixed by the following parameters:

$$
K_{p d}=\frac{3 \cdot \sigma L_{s}}{t_{r}} \quad \text { and } \quad K_{i d}=K_{p d} \cdot \frac{R_{s}}{\sigma L_{s}}
$$

\subsection{Speed control}

$i_{s q}$ current is calculated in the same way of $i_{s d}$ current. The speed internal block diagram is shown in Figure 2 for the IP structure, where as PI structure is illustrated in Figure 3. The closed TF of speed regulation with IP controller is given by the following equation: 


$$
\frac{\Omega}{\Omega^{*}}=\frac{K_{i} K_{p} K / J}{s^{2}+\left(\left(F+K_{p} K\right) / J\right) s+K_{i} K_{p} K / J}
$$

$K_{i}$ and $K_{P}$ parameters of IP speed controller are chosen in order to have the best dynamic performances. So as to fix the aimed overshoot and the settling time by imposing damping ratio $\xi$ and natural frequency $\omega_{n},(6)$ is used to calculate the $K_{i}$ and $K_{p}$ parameters to obtain the desired dynamics:

$$
K_{p}=\frac{2 \xi \omega_{n} J-F}{K} \quad \text { and } \quad K_{i}=\frac{J \omega_{n}^{2}}{K_{p} K}
$$

The closed loop TF with PI controller is given by:

$$
\frac{\Omega}{\Omega^{*}}=\frac{\left(K_{p} \cdot K / J\right) \cdot\left(s+K_{i} / K_{p}\right)}{s^{2}+\left(\left(F+K_{p} K\right) / J\right) s+K_{i} K_{p} K / J}
$$

The $K_{i}$ and $K_{P}$ parameters in function of the damping ratio $\xi$ and the natural frequency $\omega_{n}$ are given by:

$$
K_{p}=\frac{2 \xi \omega_{n} J-F}{K} \quad \text { and } \quad K_{i}=\frac{J \omega_{n}^{2}}{K}
$$

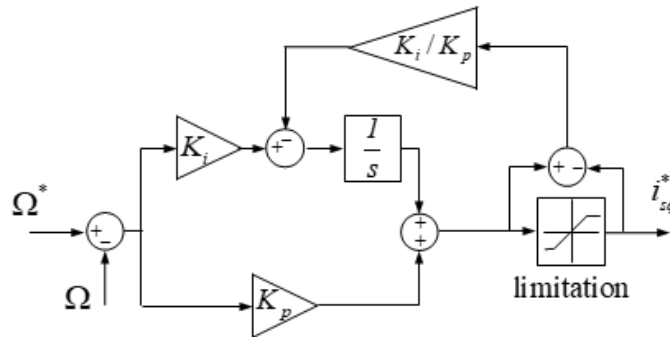

Figure 2. IP Internal structure block diagram

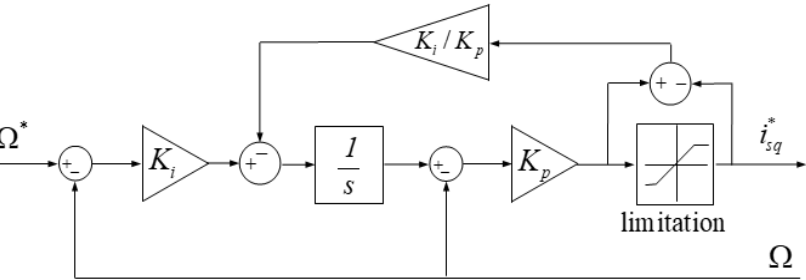

Figure 3. PI Internal structure block diagram

\section{ADVANCED SPEED CONTROLLERS}

\subsection{RST speed controller}

To impose a strong dynamic for the torque control, a RST polynomial regulator is used to control the speed. At the opposite of the conventional PI controller with only one degree of freedom, the RST controller is considered as a regulator with two degrees of freedom. It consists of a multi-objective control that easily leads to optimization of the dynamic response time and the disturbance rejection. The basic structure of the RST controller is given by Figure 4, where $A(s) / B(s)$ represents the open loop TF system.

$$
u(s)=\frac{T(s)}{S(s)} r(s)-\frac{R(s)}{S(s)} y(s)
$$

The input control signal is given by a special filtering of the output and the reference. The synthesis of the RST controller is done so that to impose a desired closed-loop TF:

$$
y(s)=\frac{B_{d}(s)}{A_{d}(s)} r(s)
$$

Let the closed loop transfer function of the block diagram of Figure 4 be:

$$
G_{B F}^{d}(s)=\frac{y(s)}{r(s)}=\frac{B(s) \cdot T(s)}{A(s) \cdot S(s)+B(s) \cdot R(s)}
$$

This transfer function must be equal to the desired closed loop function so that:

$$
\frac{B(s) \cdot T(s)}{A(s) \cdot S(s)+B(s) \cdot R(s)}=\frac{B_{d}(s)}{A_{d}(s)}
$$

The following equations have to be resolved:

$$
A(s) S(s)+B(s) R(s)=A_{d}(s) \text { and } B(s) T(s)=B_{d}(s)
$$

The following transformation is applied:

$$
\begin{aligned}
& A(s) S(s)+B(s) R(s)=B(s) A_{d}(s) \\
& T(s)=B_{d}(s)
\end{aligned}
$$


To determine $R(s)$ and $S(s)$, it is necessary to solve the BEZOUT equation:

$$
A(s) S(s)+B(s) R(s)=B(s) A_{d}(s)
$$

The placement synthesis adjustment of the RST controller is to synthesize three polynomials R, S and T on the basis of a robust pole placement. The mechanical part TF can be given by:

$$
G(s)=\frac{\Omega}{i_{s q}^{*}} \approx \frac{K}{J . s+F}
$$

The association of the RST structure with the system allows to impose a global dynamic of second order. The desired transfer function is:

$$
G_{B F}^{d}(s)=\frac{\omega_{n}^{2}}{s^{2}+2 \zeta \omega_{n} s+\omega_{n}^{2}}
$$

The polynomials $\mathrm{S}, \mathrm{R}$ and $\mathrm{T}$ are as following:

$$
S(s)=s_{0}+s_{1} s, \quad R(s)=r_{0}+r_{1} s, \quad T(s)=t_{0}
$$

The polynomials coefficients of the RST can be calculated using the Bezout equation. Thus, we obtain:

$$
s_{0}=1, \quad s_{1}=\frac{K}{J}, \quad r_{0}=\omega_{n}^{2}, \quad r_{1}=2 \zeta \omega_{n}-\frac{s_{0} J}{K}, \quad T(s)=t_{0}=\omega_{n}^{2}
$$

\subsection{Fuzzy speed controller}

Fuzzy logic controllers are able to incorporate experience, intuition and heuristics into the system and do not rely on mathematical models. However, they have high computational burden during hardware and software implementation, especially when the number of fuzzy logic inputs and the dimension of the rule base are important [32].

Fuzzy control techniques have been explored and used by several researchers. It has gained great attention in the area of electromechanical devices. This is due to its potential to improve the speed regulation of the drive system. Because of its ability to incorporate the human intuition in design process and linguistic rules with an 'if-then' structure [6].

The proposed adaptive fuzzy controller (AFC) showed in Figure 5 is based on Sugeno method thanks to its computational efficiency and it is well suited for linear technique, such as PI conventional controllers. The main difference between Mamdani and Sugeno is that the Sugeno output membership functions are either linear or constant. Inputs are the error between the actual and the reference speed, its first derivative and the $V_{s a t}$ variable due to the saturation of $i_{s q}$ as shown in Figure 6 . Their expressions are thus underneath:

$$
\left\{\begin{array}{c}
E_{r}(t)=\Omega^{*}(t)-\Omega(t) \\
d E_{r}(t)=E_{r}(t)-E_{r}(t-1)\{ \\
V_{s a t}=I_{s q m a x}^{* *}
\end{array}\right.
$$

Output is the weight to be used in order to adapt the $\boldsymbol{P I}$ controller by adjusting in real time proportional and integral action using the center of gravity method as follows:

$$
W=\frac{\sum_{i=1}^{n} c_{i} \cdot \mu_{i}}{\sum_{i=1}^{n} \mu_{i}}
$$

Scale factors gains defined as GEr, GdEr, Gsat, GW_Integ and GW_Prop are used to make the AFC sensitive and near to the normalized defined input and output range values. Input variables fuzzy set are Negative: N. Positive: P. Zero: Z. The values range of output variables are: Zero: Z. Positive normal: PN. Positive Big: PB.

The following heuristic considerations have been noted from the observation of the process behavior: Integral action: Overshoot is mainly caused by integral term. Significant reduction causes system response to exceed the set point, Proportional action: Increasing proportional term reduces the leading time but increases the oscillations, Saturation: A variable depending on isq current is introduced for limitations due to the saturation. Table 1 gives the rules used for this AFC. The use of triangular membership functions for the inputs and singleton in output is advantageous for time calculation asn shown in Figure 6 and Figure 7. The AFC speed surface is presented in Figure 8. 

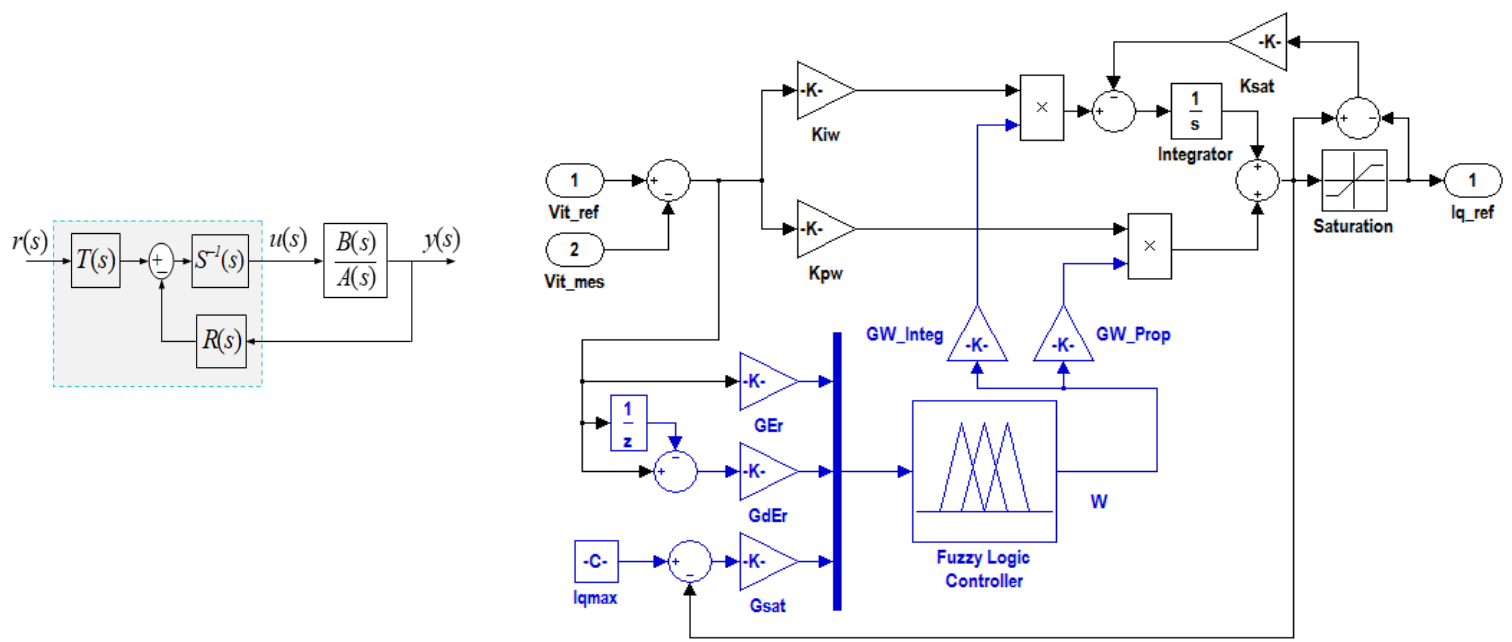

Figure 4. RST controller block diagram
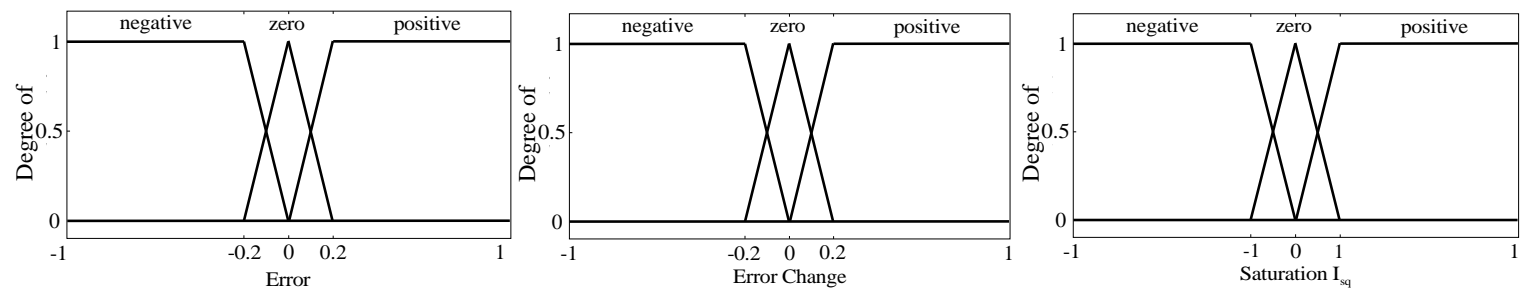

Figure 6. Input membership functions of the $A F C$

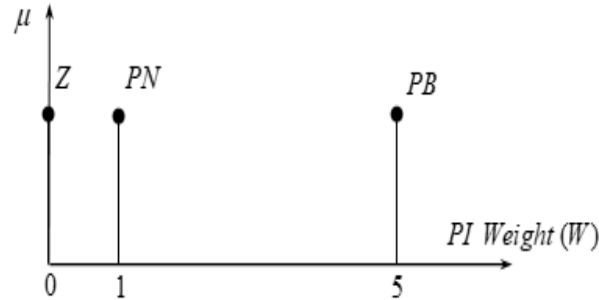

Figure 7. Output membership functions of the AFC

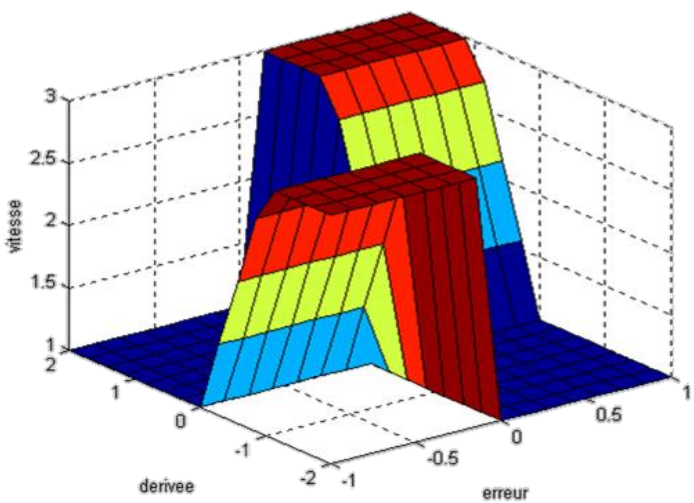

Figure 8. Speed AFC surface

Table 1. A FC rules

\begin{tabular}{cccc}
\hline \multicolumn{3}{c}{ Inputs } & \multirow{2}{*}{ Output $W$} \\
\hline$E_{r}$ & $d E_{r}$ & $V_{\text {sat }}$ & $\boldsymbol{Z}$ \\
$N$ & $/$ & $N$ & $\boldsymbol{P B}$ \\
$P$ & $/$ & $P$ & $\boldsymbol{P B}$ \\
$P$ & $/$ & $N$ & $\boldsymbol{Z}$ \\
$Z$ & $/$ & $P$ & $\boldsymbol{P N}$ \\
$/$ & $/$ & $/$ & $\boldsymbol{P N}$ \\
$/$ & $Z$ & $Z$ & $\boldsymbol{P N}$ \\
$N$ & $N$ & $/$ & $\boldsymbol{P B}$ \\
\hline
\end{tabular}

\section{EXPERIMENTAL RESULTS AND DISCUSSION}

The experimental test bench developed in LIAS laboratory is composed by DS1104 board, squirrel cage IM (LEROYSOMER LS 90), DC generator supplying a resistor used as a dynamic load, three-phase IGBT inverter allowing the realization of different power supply modes, current measurement module, speed 
sensors and PC with Matlab/Simulink and control-desk program. Figure 9 shows the experimental test bench and Figure 10 presents its different parts. The controller is built through Simulink block diagram. The MATLAB real time workshop routine produces C-code from Simulink block diagram. $10 \mathrm{KHz}$ space vector Modulation (SVM) algorithm was used to drive the three-phase inverter. The interface between Simulink and the dSPACE1104 allows the control algorithms to be run on the hardware. With control-desk, it is possible to change controller parameters and reference signals while an experiment is running. To reduce the time calculation, Simulink lookup table models were used to realize the fuzzy rules.

Different test cases were completed in the laboratory under different operating conditions in order to evaluate the performances of the proposed $A F C$ and RST controllers. Two benchmarks were proposed. The first one is for step reference in order to evaluate the dynamic performances of each developed speed controller. The second one is for speed ramp inversion benchmark at nominal conditions and it is used to study the system behaviors in terms of trajectory tracking.
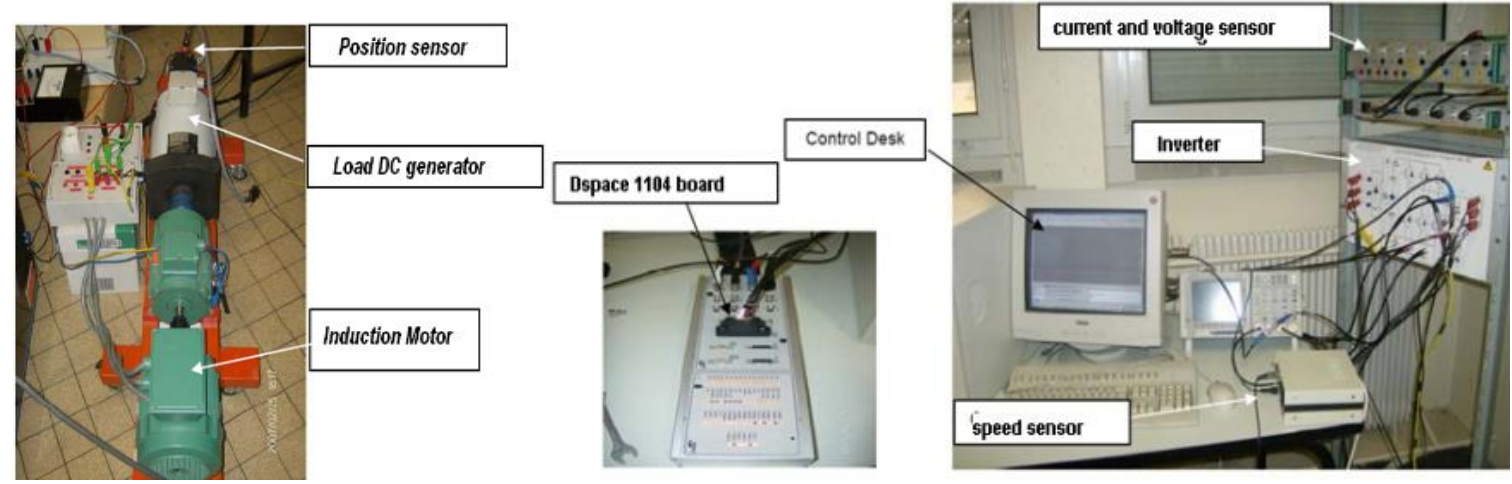

Figure 9. Experimental test benches

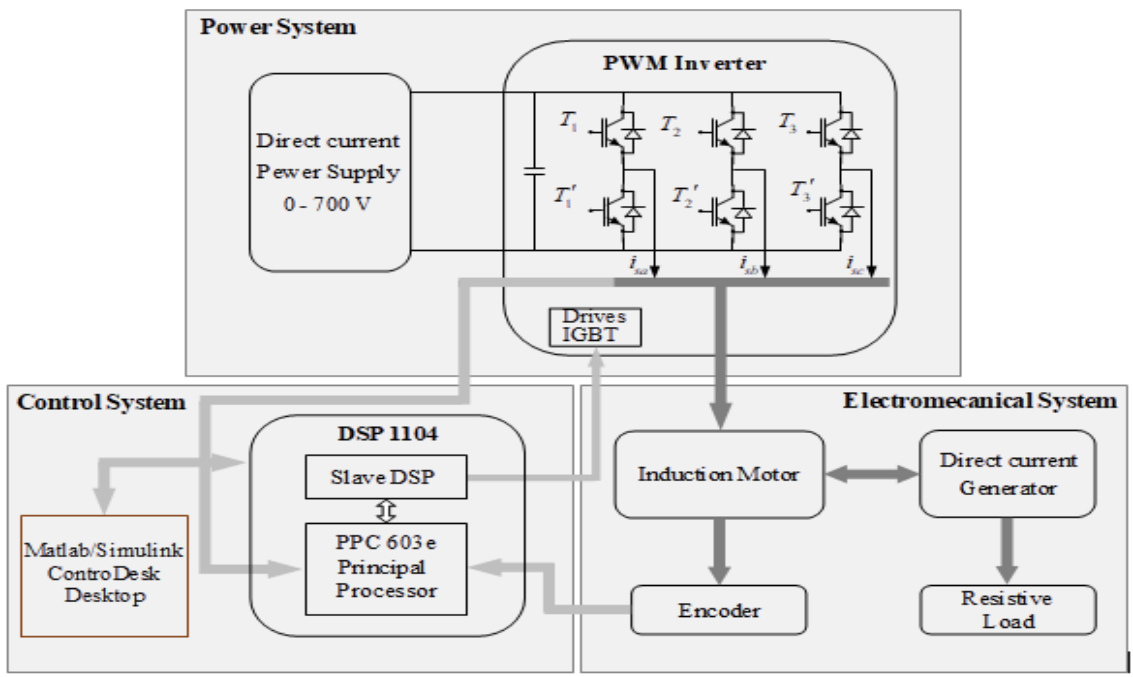

Figure 10. Experimental test bench schemes

The closed-loop control system would be stable and would meet tracking performance (rise time, overshoot, and settling time) at transient, regulation performance (load disturbance rejection) at steady state. For the step tracking trajectory, the speed is imposed between +500 and $-500 \mathrm{rpm}$. The nominal load disturbance torque was applied and removed for the positive and negative speed reference. The experimental results are presented in Figure 11, Figure 12 and Figure 13.

The ramp benchmark at nominal conditions imposes a speed inversion between +1400 and -1400rpm. The results are also illustrated in Figure 14, Figure 15 and Figure 16. The tracking performance is obtained including steady state, speed inversion and load disturbance rejection. Several experimental tests were realized for different gains values. 

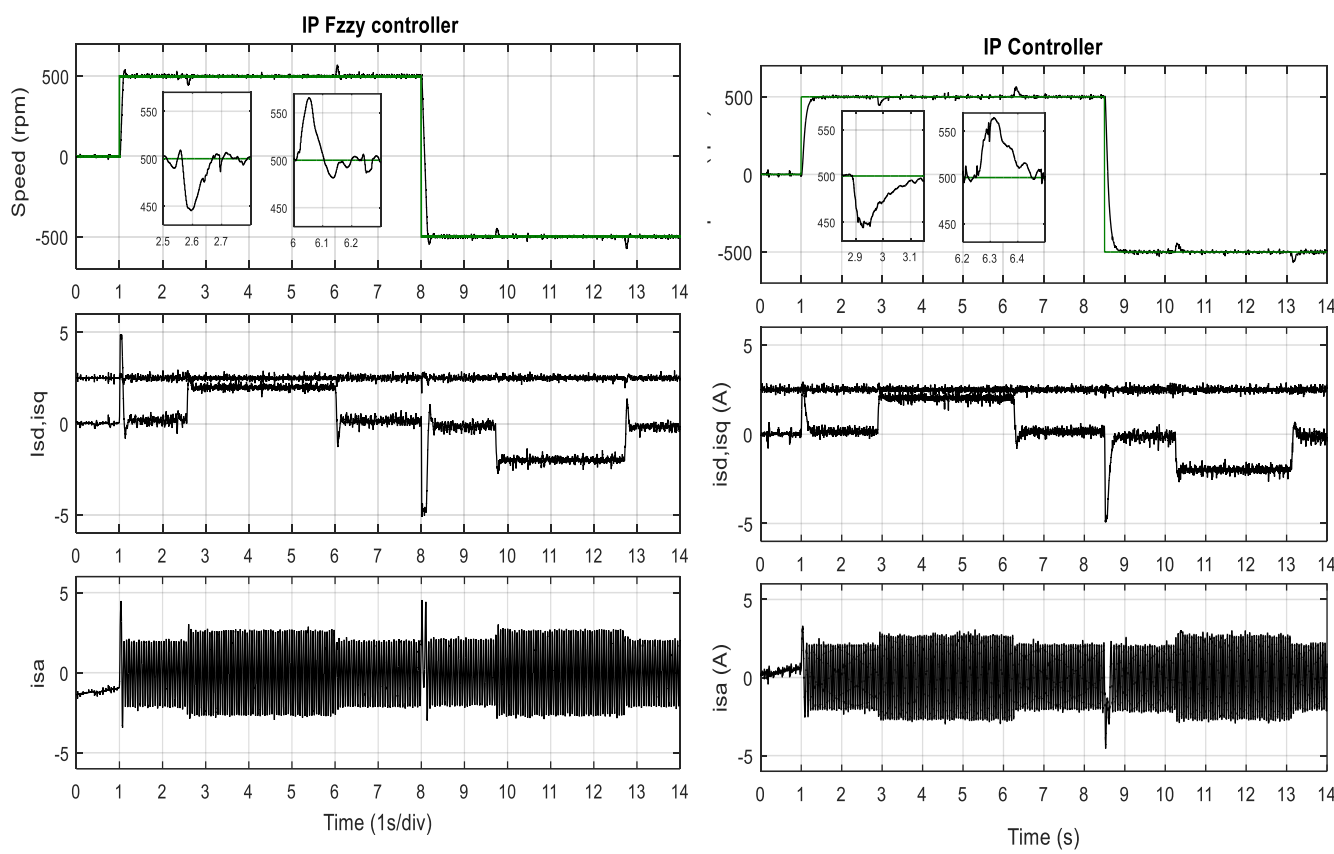

Figure 11. Performances of conventional IP and AFC-IP controllers in case of step benchmark
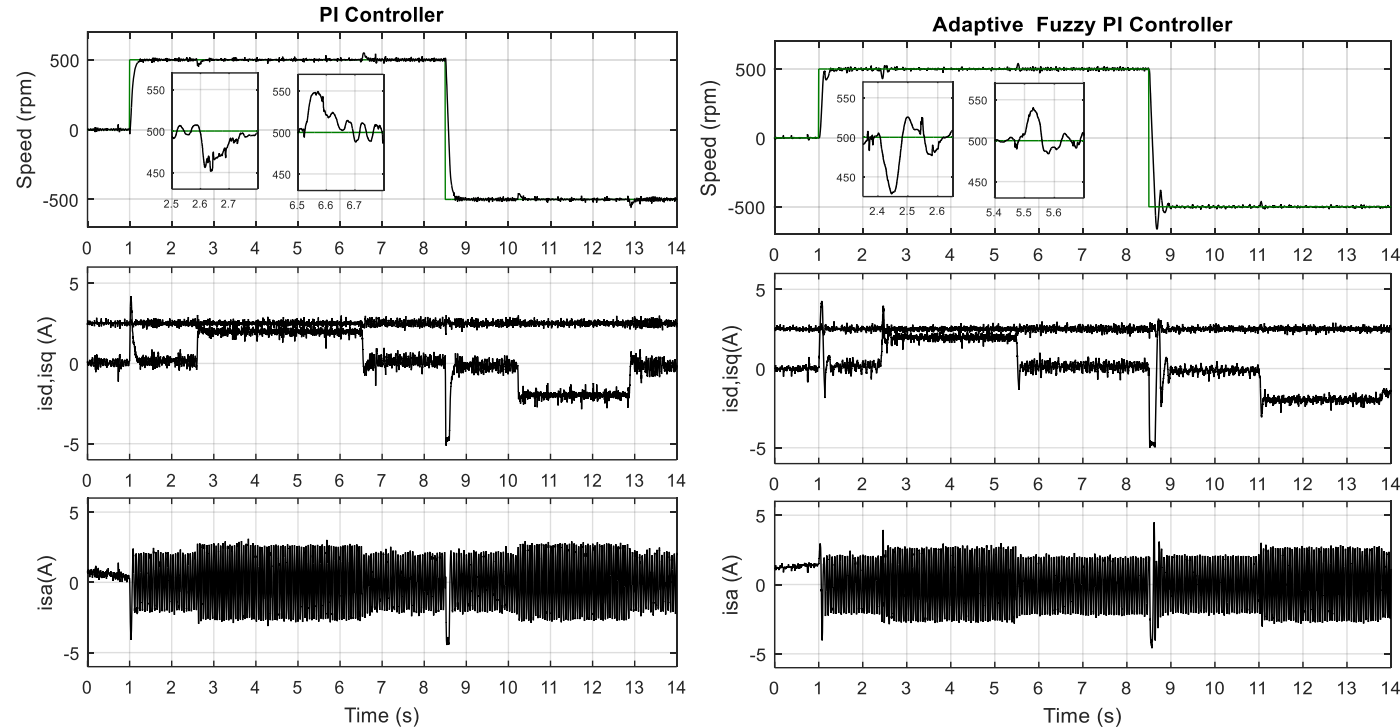

Figure 12. Performances of conventional PI and AFC-PI controllers for step benchmark

The best gains PI and IP speed controllers successfully implemented are given in Table 2. In the same way, the chosen AFC scale factors gains are given in Table 3, whereas the Table 4 contains the RST polynomials coefficients. It can clearly be seen that AFC and RST speed controllers have faster tracking characteristics than PI and IP conventional speed controllers. The RST provides best-induced error reduction for load disturbance rejection. The obtained dynamic performances (rise time, settling time, overshoot) are shown in Table 5.

To confirm the robustness of the proposed AFC and RST speed controllers against conventional used controllers, different experimental parameters variation tests were developed for each controller. For the rotor resistance, the variation was done between $70 \%$ and $150 \%$. The inertia moment $\mathrm{J}$ variation was done between $70 \%$ and $130 \%$ for conventional and AFC controllers. The results are presented in Figure 17 and Figure 18. With the RST speed controller, the variation was done until $50 \%$ for the rotor resistance and until $170 \%$ for the inertia moment. Obtained results are also shown in Figure 19. Best results were provided with AFC and 
RST speed controllers, which confirms the robustness against parameters variation. In particular, dynamic performances of RST speed controller were conserved. The used IM parameters are also given in Table 6.

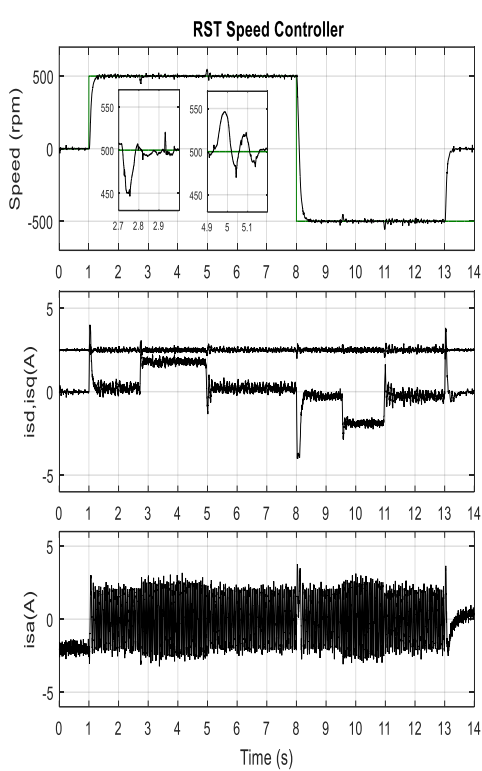

Figure 13. Performances of RST controller for step benchmark
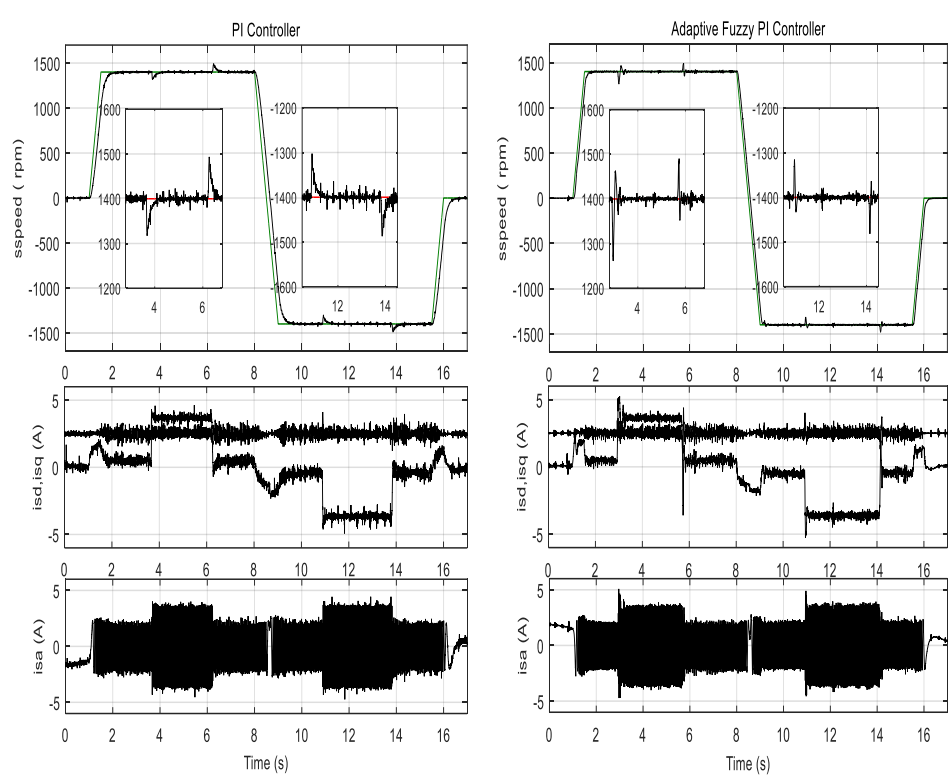

Figure 15. Performances of conventional PI and AFC-PI controllers for ramp benchmark

Table 2. IP and PI parameters

\begin{tabular}{ccc}
\hline & IP & PI \\
\hline $\mathrm{K}_{\mathrm{p}}$ & 0.1350 & 0.0870 \\
$\mathrm{~K}_{\mathrm{i}}$ & 10.2300 & 0.5872 \\
\hline
\end{tabular}
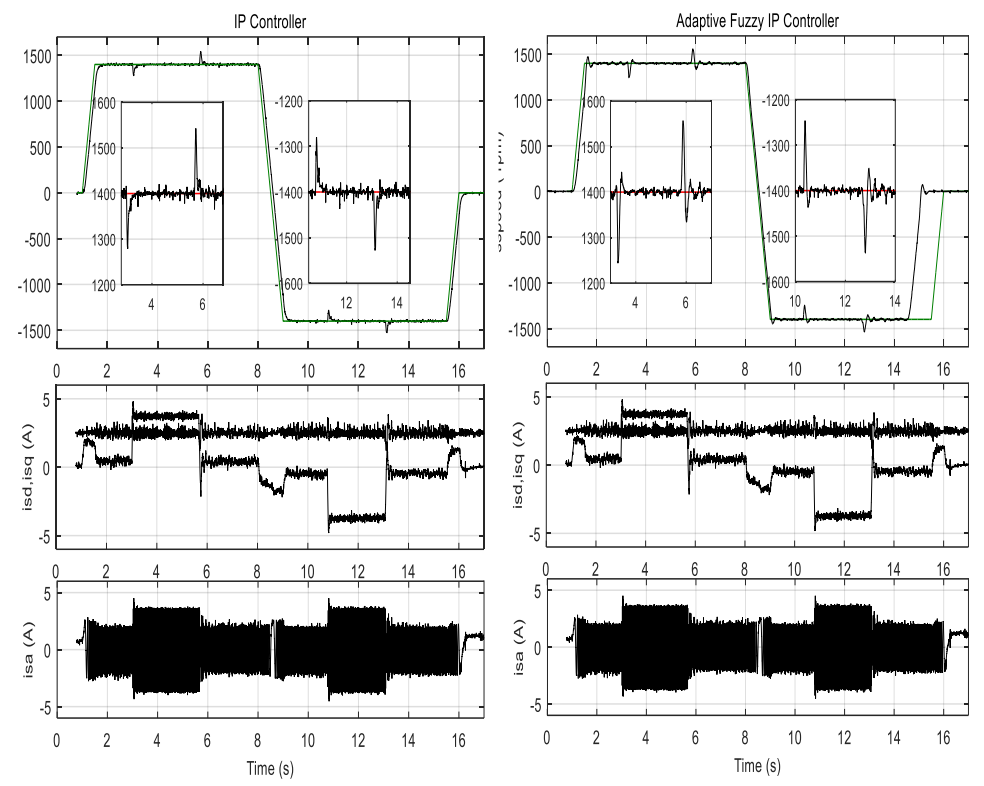

Figure 14. Performances of conventional IP and AFC-IP controllers in case of ramp benchmark

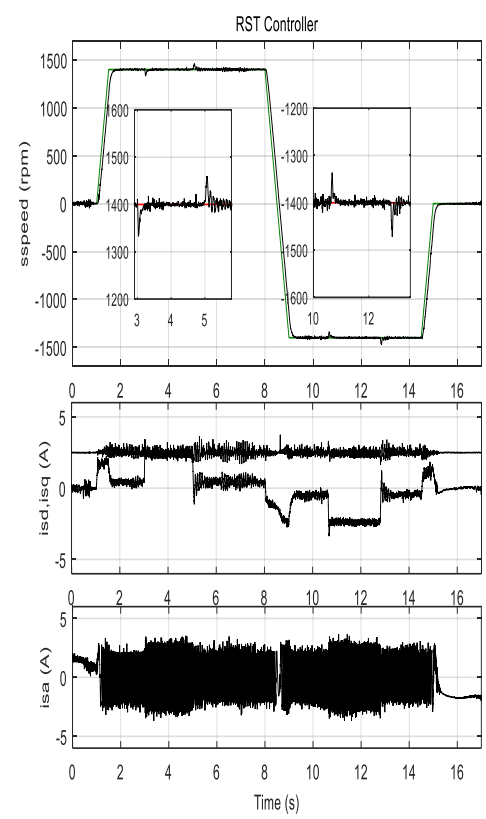

Figure 16. Performances of RST controller for ramp benchmark

\begin{tabular}{cc} 
Table 4. RST coefficients \\
\hline Coefficients & Values \\
\hline $\mathrm{s}_{0}$ & 1 \\
$\mathrm{~s}_{1}$ & 117.7158 \\
$\mathrm{r}_{0}$ & 625 \\
$\mathrm{r}_{1}$ & 35.3415 \\
$\mathrm{t}_{0}$ & 625 \\
\hline
\end{tabular}



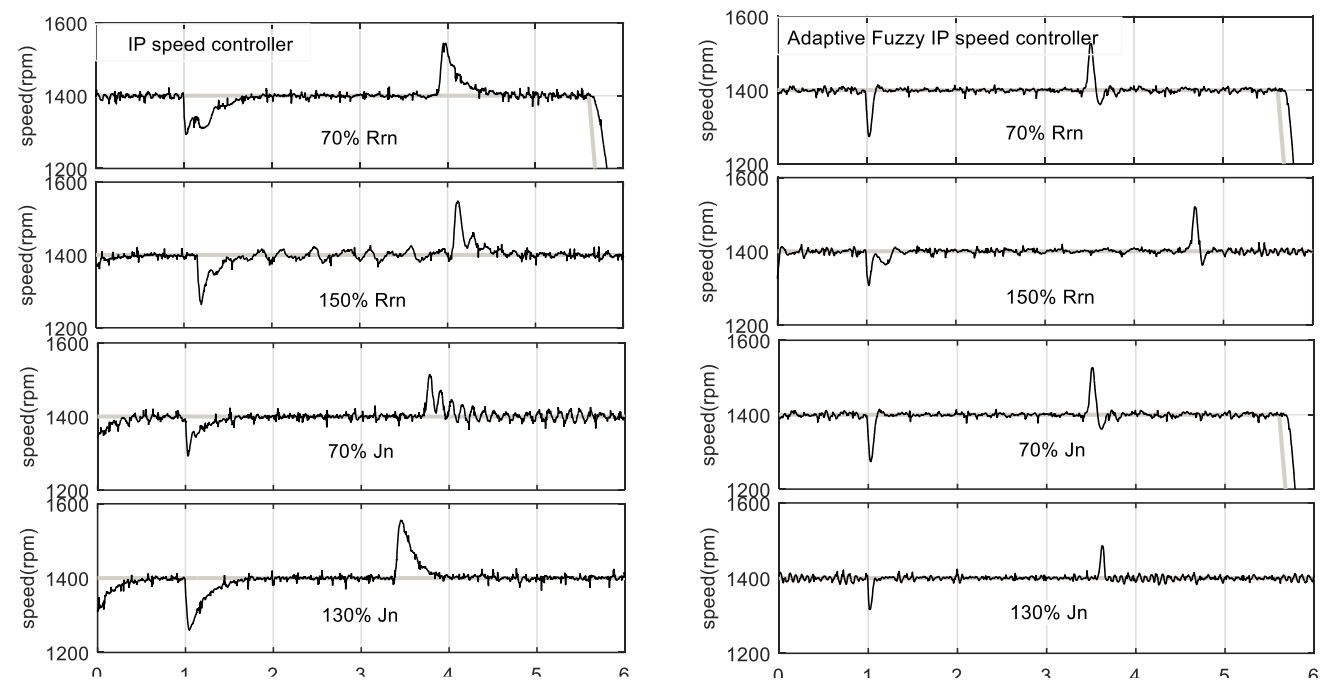

Figure 17. Robustness tests of conventional IP and AFC-IP controllers
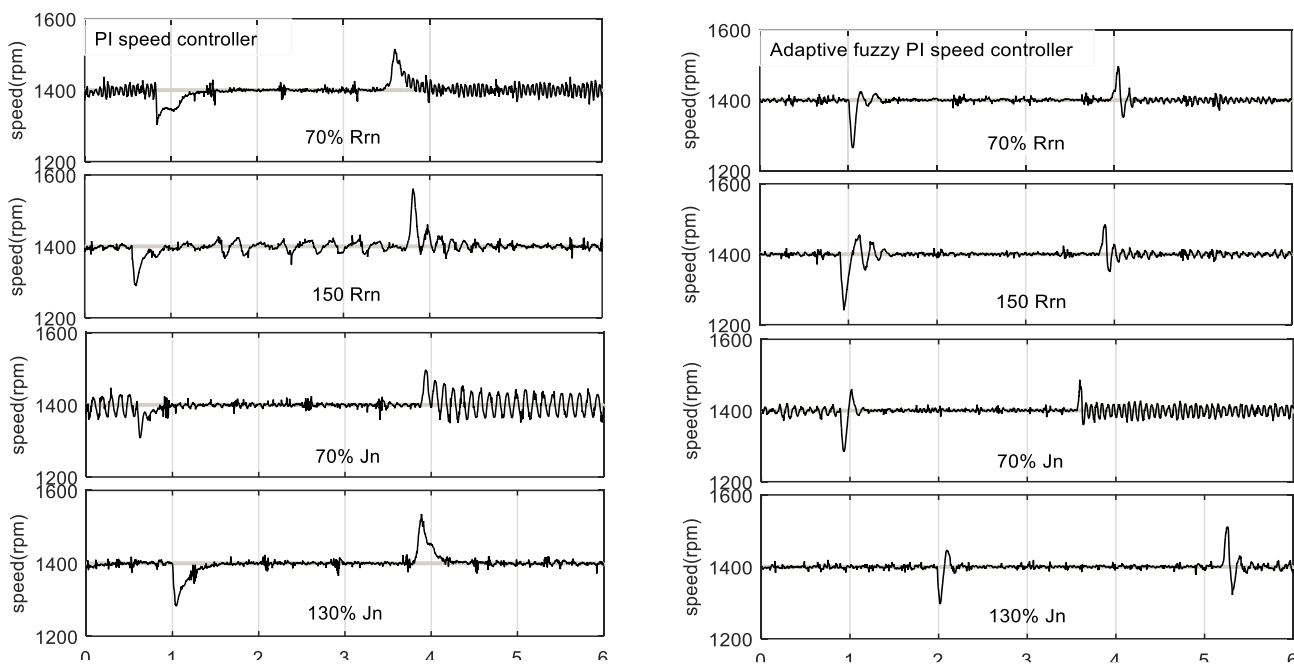

Figure 18. Robustness tests of the conventional PI and AFC-PI controllers

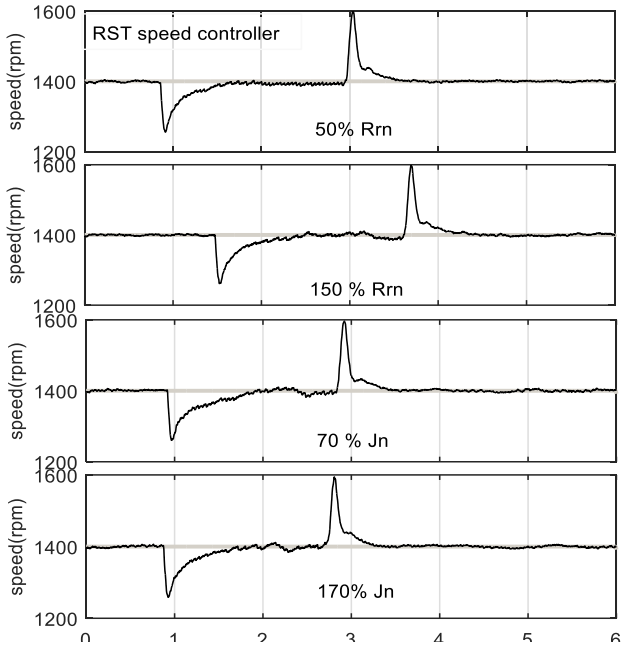

Figure 19. Robustness tests of conventional RST controller 
Table 5. Experimental results of controller's dynamic performances

\begin{tabular}{cccc}
\hline $\begin{array}{c}\text { Speed } \\
\text { controllers }\end{array}$ & $\begin{array}{c}\text { Rise time } \\
(\mathrm{s})\end{array}$ & $\begin{array}{c}\text { Settling } \\
\text { time }(\mathrm{s})\end{array}$ & $\begin{array}{c}\text { Overshoot } \\
(\%)\end{array}$ \\
\hline IP & 0.1430 & 0.2070 & 0 \\
AFC-IP & 0.0580 & 0.0780 & 7 \\
PI & 0.1110 & 0.1600 & 0 \\
AFC-PI & 0.0710 & 0.1140 & 0 \\
RST & 0.0510 & 0.1400 & 0 \\
\hline
\end{tabular}

Table 6. IM parameters

\begin{tabular}{lcc}
\hline \multicolumn{1}{c}{ Type } & \multicolumn{1}{c}{$\begin{array}{c}\text { Squirrel Cage Induction } \\
\text { Motor }\end{array}$} \\
\hline Rated Power & & $1.1 \mathrm{KW}$ \\
Rated Frequency & $2 p$ & $50 \mathrm{~Hz}$ \\
Number of Poles & $M_{s r}$ & $0.4475 \mathrm{H}$ \\
Mutual inductance & $L_{s}$ & $471.8 \mathrm{mH}$ \\
Stator inductance & $L_{r}$ & $471.8 \mathrm{mH}$ \\
Rotor inductance & $R_{s}$ & $9.6500 \Omega$ \\
Stator resistance & $R_{r}$ & $4.3047 \Omega$ \\
Rotor resistance & $J$ & $29.310^{-3} \mathrm{Kg} \cdot \mathrm{m}^{2}$ \\
Inertia Moment & $F$ & $13.010^{-3} \mathrm{Nm} / \mathrm{rad}^{-1}$ \\
Friction Coefficient & &
\end{tabular}

\section{CONCLUSION}

This work reports successful development and implementation of RST and AFC speed controller to improve the indirect FOC of IM drive system. Experimental obtained results show that both PI and IP structures give good response when the AFC provides better closed-loop tracking performances under external disturbances, such as load changes and speed inversion. The use of linear and constant membership functions makes the AFC implementation simple and advantageous in terms of calculation time. However, the RST speed controller accelerates the response time without overshoot thanks to proper poles placement. All tests show that AFC and RST speed controllers provide fast and robust speed settlings compared to the PI/IP conventional controllers. Robustness tests confirm their efficiency. In perspective, the proposed RST and AFC speed controllers can be combined with a new configuration using the fuzzy adaptation mechanism to act on the calculation of the RST polynomial parameters.

\section{ACKNOWLEDGEMENTS}

The authors would like to thank Professor Gérard Champenois for his help and his contribution to the experimental setup completely realized at LIAS laboratory of the University of Poitiers, France.

\section{REFERENCES}

[1] J. Bocker and S. Mathapati, "State of the Art of Induction Motor Control," 2007 IEEE International Electric Machines \& Drives Conference, Antalya, Turkey, 2007, pp. 1459-1464, doi: 10.1109/IEMDC.2007.383643.

[2] S. A. Odhano, R. Bojoi, A. Boglietti, Ş. G. Roşu and G. Griva, "Maximum Efficiency per Torque Direct Flux Vector Control of Induction Motor Drives," in IEEE Transactions on Industry Applications, vol. 51, no. 6, pp. 4415-4424, Nov.-Dec. 2015, doi: 10.1109/TIA.2015.2448682.

[3] W. Leonhard, "Control of Electrical Drives," Springer-Verlag, 3rd edition, Berlin, Germany, ISBN: 9783540418207, September 21, 2001.

[4] K. J. Aström, T. Hägglund. "PID Controllers: Theory, Design and Tuning," Instrument Society of America, USA, 2nd edition, ISBN: 1-55617-516-7, 1995.

[5] B. Chen, W. Yao, F. Chen and Z. Lu, "Parameter Sensitivity in Sensorless Induction Motor Drives With the Adaptive Full-Order Observer," in IEEE Transactions on Industrial Electronics, vol. 62, no. 7, pp. 4307-4318, July 2015, doi: 10.1109/TIE.2014.2388197.

[6] R. Krishnan and A. S. Bharadwaj, "A review of parameter sensitivity and adaptation in indirect vector controlled induction motor drive systems," in IEEE Transactions on Power Electronics, vol. 6, no. 4, pp. 695-703, Oct. 1991, doi: 10.1109/63.97770.

[7] L. Zarri et al., "Detection and Localization of Stator Resistance Dissymmetry Based on Multiple Reference Frame Controllers in Multiphase Induction Motor Drives," in IEEE Transactions on Industrial Electronics, vol. 60, no. 8, pp. 3506-3518, Aug. 2013, doi: 10.1109/TIE.2012.2235393.

[8] Y. A. Al-Turki, H. Al-Umari, "Application of the reference frame theory to the dynamic analysis of a three-phase induction motor fed from a single-phase supply," Electric Power Systems Research, vol. 53,n 3, pp. 149-156, 2000.

[9] R. Dhanasekar, S. G. Kumar and M. Rivera, "Sliding mode control of electric drives/review," 2016 IEEE International Conference on Automatica (ICA-ACCA), Curico, Chile, 2016, pp. 1-7, doi: 10.1109/ICAACCA.2016.7778466.

[10] M. Habbab, A. Hazzab, P. Sicard, "Real Time Implementation of Fuzzy Adaptive PI-sliding Mode Controller for Induction Machine Control," International Journal of Electrical and Computer Engineering (IJECE), Vol. 8, $\mathrm{n}^{\circ} .5$, pp. 2883-2893, October 2018.

[11] A. Mechernene, M. Loucif, M. Zerikat,"Induction Motor Control Based On A Fuzzy Sliding Mode Approach," Revue roumaine des sciences techniques, Électrotechnique et Énergétique, vol. 64, no.1, pp. 39-44, Bucarest, 2019 
[12] A. Zaafouri, C. Ben Regaya, H. Ben Azza, A. Châari, "DSP-based adaptive Backstepping using the tracking errors for high performance sensorless speed control of induction motor drive," ISA Transactions Elsevier,vol. 60, pp. 333-347, January 2016.

[13] Y. Zahraoui, M. Akherraz, C. Fahassa, S. Elbadaoui, " Induction motor harmonic reduction using space vector modulation algorithm," Bulletin of Electrical Engineering and Informatics, vol. 9, no. 2, pp. 452-465, April 2020.

[14] M. A. Duarte-Mermoud, J.C. Travieso-Torres, I.S. Pelissier, H. A. González, "Induction motor control based on adaptive passivity," Asian Journal of Control, vol. 14, n 1, pp. 67-84, January 2012.

[15] X. Fu and S. Li, "A Novel Neural Network Vector Control Technique for Induction Motor Drive," in IEEE Transactions on Energy Conversion, vol. 30, no. 4, pp. 1428-1437, Dec. 2015, doi: 10.1109/TEC.2015.2436914.

[16] F. F. M. El-Sousy, "Adaptive Dynamic Sliding-Mode Control System Using Recurrent RBFN for HighPerformance Induction Motor Servo Drive," in IEEE Transactions on Industrial Informatics, vol. 9, no. 4, pp. 1922-1936, Nov. 2013, doi: 10.1109/TII.2013.2238546.

[17] F. Martínez, C. Penagos, L. Pacheco, "Scheme for motion estimation based on adaptive fuzzy neural network," TELKOMNIKA Telecommunication, Computing, Electronics and Control, vol. 18, no. 2, pp. 1030-1037, April 2020.

[18] Y.Yang, W.G. Wang, "A fuzzy parameters adaptive PID controller design of digital positional servo system,"The Irst International Conference on Machine Learning and Cybernetics, Beijing, China, 4-5November, 2002.

[19] K. Zeb, Z. Ali, K. Saleem, W. Uddin, M.A. Javed, N. Christofides, "Indirect field-oriented control of induction motor drive based on adaptive fuzzy logic controller," Electrical Engineering, Springer, Issue 3, pp.803-815, 2017.

[20] H. R. Khoei, E. F. Shahraki, "Fuzzy Logic Based Direct Power Control of Induction Motor Drive," Bulletin of Electrical Engineering and Informatics, vol. 5, no. 3, pp. 296-306, September 2016.

[21] A. Taieb, A. Ferdjouni, "A new design of fuzzy logic controller optimized by PSO-SCSO applied to SFO-DTC induction motor drive," International Journal of Electrical and Computer Engineering (IJECE), vol. 10, no. 6, pp. 5813-5823, December 2020.

[22] H. Maghfiroh, C. Hermanu, M. H. Ibrahim, M. Anwar, A. Ramelan, "Hybrid fuzzy-PID like optimal control to reduce energy consumption," TELKOMNIKA Telecommunication, Computing, Electronics and Control, vol. 18, no. 4, pp. 2053-2061, August 2020.

[23] K. Kouzi, L. Mokrani , M.S. Nait-Said, "A new design of fuzzy logic controller with fuzzy adapted gains based on indirect vector control for induction motor drive," IEEE Proceedings of the 35th Southeastern Symposium on System Theory, Morgantown, WV, USA, March 16-18, 2003.

[24] B. Dahhou, M. Bendjebbar, S. Lachtar, " Improvement of adaptive fuzzy control to adjust speed for a doubly fed induction motor drive (DFIM)," International Journal of Power Electronics and Drive System (IJPEDS), vol. 11, no. 1, pp. 496-504, March 2020.

[25] M. Masiala, B. Vafakhah, John Salmon, A M. Knight, "Fuzzy Self-Tuning Speed Control of an Indirect FieldOriented Control Induction Motor Drive," IEEE Transactions on Industry Applications, vol. 44, no. 6, pp.17321740, 2008.

[26] M. Tursini, F. Parasiliti, D. Zhang, "Real-time gain tuning of PI controllers for high-performance PMSM drives," IEEE Transactions on Industry Applications, vol. 38, no. 4, pp. 1018-1026, 2002.

[27] A. Hazzab, I. K. Bousserhane, M. Zerbo, P. Sicard, "Real Time Implementation of Fuzzy Gain Scheduling of PI Controller for Induction Motor Machine Control," Neural Processing Letters, Springer, vol. 24, n 3, pp. 203-215, 2006.

[28] A. Rubaai, M. J. Castro-Sitiriche and A. R. Ofoli, "Design and Implementation of Parallel Fuzzy PID Controller for High-Performance Brushless Motor Drives: An Integrated Environment for Rapid Control Prototyping," in IEEE Transactions on Industry Applications, vol. 44, no. 4, pp. 1090-1098, July-aug. 2008, doi: 10.1109/TIA.2008.926059.

[29] B. Heber, L. Xu, Y. Tang, "Fuzzy logic enhanced indirect field oriented control of induction machine," IEEE Transactions on Power Electronics, vol. 12, no. 5,pp. 772-778, 1997.

[30] F. Nabil, M. H. N. Talib, Z. Ibrahim, J. M. Lazi, A. Maaspaliza, "Self-tuning Fuzzy Logic Controller Based on Takagi-Sugeno Applied to Induction Motor Drives," International Journal of Power Electronics and Drive System (IJPEDS), vol. 9, no. 4, pp. 1967-1975, December 2018.

[31] M. N. Uddin, T. S. Radwan and M. A. Rahman, "Performances of fuzzy-logic-based indirect vector control for induction motor drive," in IEEE Transactions on Industry Applications, vol. 38, no. 5, pp. 1219-1225, Sept.-Oct. 2002, doi: 10.1109/TIA.2002.802990.

[32] B. M, B. Mazari,"Neuro-fuzzy controller used to control the speed of an induction motor," CATEE'2002, Oman Jordanie, 19-21 Mars 2002.

[33] Y. Mihoub, D. Toumi, B. Mazari, S. Hassaine, "Design and Implementation of an adaptive PI fuzzy controller t improve the speed control of induction motor," International Review of Electrical (IREE), vol. 5, no. 2, pp. 481490, 2010B.

[34] Meliani, A. Meroufel, "Direct space vector modulation for matrix converter fed dual star induction machine and neuro-fuzzy speed controller," Bulletin of Electrical Engineering and informatics, vol.8, no. 3, pp. 818-828, 2019.

[35] H. R. Khoei, E. F. Shahraki, "Fuzzy based direct power control of induction Motor drive," Bulletin of Electrical Engineering and informatics, vol.5, no. 3, pp. 296-306, 2016.

[36] M. H. N. Talib, Z. Ibrahim,N. Abd. Rahim,A. S. Abu Hasim, H. Zainuddin, "Performance improvement of induction motor drive using simplified FLC method," IEEE 16th International Power Electronics and Motion Control Conference and Exposition, Antalya, Turkey, 2014.

[37] J. D. Landau, "Commande des systèmes : conception, identification et mise en œuvre," Hermès, Paris, 2002. 
[38] R. Longchamp, "Commande numérique des systèmes dynamiques," Presses Polytechniques et Universitaire Romandes, Lausanne, vol. 1, 2010.

[39] N. Akkari, A. Chaghi, R. Abdessemed, "Study and Simulation of RST Regulator Applied to a Double Fed Induction Machine (DFIM)," Journal of Electrical Engineering \& Technology, vol. 3, no. 3, pp.308-313, 2008.

\section{BIOGRAPHIES OF AUTHORS}

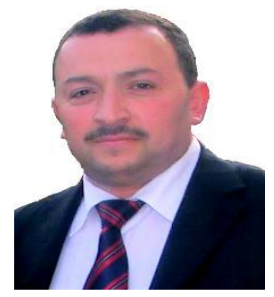

Youcef Mihoub graduated with his PhD degree in Electrical Engineering from the Sciences and Technology University of Oran in Algeria. He is actually a Professor in the Electrical Engineering Department of Ibn Khaldoun University of Tiaret in Algeria. He is also a member of the Laboratory of Energetic Engineering and Computer Engineering (L2GEGI) at the same university His main research area focuses on artificial intelligence techniques in electrical control and in particular fuzzy control and neural networks. Email: Youcef.mihoub@univtiaret.dz

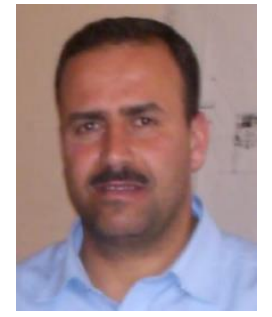

Djilali Toumi graduated with his PhD degree in from the Sciences and Technology University of Oran in Algeria. He is actually a Professor in the Electrical Engineering Department of Ibn Khaldoun University of Tiaret in Algeria. He is also a member of the Laboratory of Energetic Engineering and Computer Engineering (L2GEGI) at the same university. His main research area focuses on advanced techniques in electrical control and diagnosis with intelligent control in particular neural networks. Email: Djilali.toumi@univ-tiaret.dz

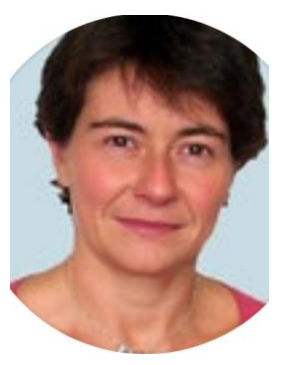

Sandrine Moreau was born in france in 1972. She received the Ph.D degree from the University of Poitiers in automatic control in 1999. She is now Professor at the Unniversity of Poitiers (France). Her major research interests are modelling; identification, diagnosis and control of electrical machines associated with static converters. Email: Sandrine.Moreau @univ-poitiers.fr

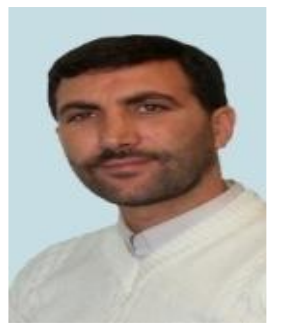

Said Hassaine received his $\mathrm{PhD}$ degree in Electrical Engineering from the Sciences and Technology University of Oran in Algeria. He is currently a Professor in the Electrical Engineering Department and he is also a member of the Laboratory of Energetic Engineering and Computer Engineering (L2GEGI) both at the Ibn Khaldoun University of Tiaret in Algeria. His main research interests are on the application of new control techniques in power electronics. Email: Said.hassaine@univ-tiaret.dz

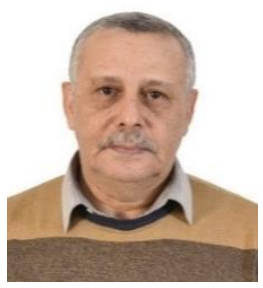

Bachir Daoud prepared his PhD his Phd in biometrics subject: "Bandelet-based multimodel biometrics: face and fingprint between 2010 and 2014. He obtained his master's degree in electrical engineering (QPR 3.45) a Brigeport University Connecticut USA He is currently a Professor in the computer department in mathematics and computer Faculty, Ibn Khaldoun University His main research interests is on the application of image processing, control techniques in power electronics and signal processing theory. Email: Bachir.daoud@univtiaret.dz 